Article

\title{
Chromium Carbide Growth by Direct Liquid Injection Chemical Vapor Deposition in Long and Narrow Tubes, Experiments, Modeling and Simulation
}

\author{
Alexandre Michau ${ }^{1}$ (D), Francis Maury ${ }^{2}$, Frederic Schuster ${ }^{3}$, Ioana Nuta ${ }^{4}$, Yoan Gazal ${ }^{2}$, \\ Rapahel Boichot ${ }^{4}$ and Michel Pons ${ }^{4, *}$ \\ 1 DEN Service d'Etudes Analytiques et de Réactivité des Surfaces (SEARS), CEA, Université Paris-Saclay, \\ 91191 Gif Sur Yvette, France; Alexandre.Michau@cea.fr \\ 2 CIRIMAT, Université de Toulouse, CNRS/INPT/UPS, 4 allée E. Monso, 31030 Toulouse, France; \\ francis.maury@ensiacet.fr (F.M.); yoan.gazal@ensiacet.fr (Y.G.) \\ 3 Cross-Cutting Program on Materials and Processes Skills Department, CEA, Université Paris-Saclay, \\ 91191 Gif Sur Yvette, France; frederic.schuster@cea.fr \\ 4 Institute of Engineering, Université Grenoble Alps, CNRS, Grenoble INP, SIMAP, 38000 Grenoble, France; \\ ioana.nuta@simap.grenoble-inp.fr (I.N.); raphael.boichot@grenoble-inp.fr (R.B.) \\ * Correspondence: michel.pons@simap.grenoble-inp.fr
}

Received: 24 May 2018; Accepted: 8 June 2018; Published: 13 June 2018

\begin{abstract}
Chromium carbide layers were deposited using liquid-injection metal-organic chemical vapor deposition inside long ( 0.3 to $1 \mathrm{~m}$ ) and narrow ( 8 to $24 \mathrm{~mm}$ in diameter) metallic tubes. The deposition was carried out using a molecular single-source, bis(benzene)chromium (BBC), as representative of the bis(arene)metal family diluted in toluene and injected with $\mathrm{N}_{2}$ as carrier gas. A multicomponent mass transport model for the simulation of the coupled fluid flow, heat transfer and chemistry was built. The kinetic mechanism of the growth of $\mathrm{CrC}_{x}$ films was developed with the help of large-scale experiments to study the depletion of the precursors along the inner wall of the tube. The model fits well in the $400-550{ }^{\circ} \mathrm{C}$ temperature range and in the $1.3 \times 10^{2}$ to $7 \times 10^{3} \mathrm{~Pa}$ pressure range. The pressure is shown to have a pronounced effect on the deposition rate and thickness uniformity of the resulting coating. Below $525{ }^{\circ} \mathrm{C}$ the structure, composition and morphology of the films are not affected by changes of total pressure or deposition temperature. The coatings are amorphous and their $\mathrm{Cr}: \mathrm{C}$ ratio is about 2:1, i.e., intermediate between $\mathrm{Cr}_{7} \mathrm{C}_{3}$ and $\mathrm{Cr}_{3} \mathrm{C}_{2}$. The model was applied to the design of a long reactor $(1 \mathrm{~m})$, with a double injection successively and alternatively undertaken at each end to ensure the best uniformity with sufficient thickness. This innovative concept can be used to optimize industrial deposition processes inside long and narrow tubes and channels.
\end{abstract}

Keywords: metalorganic chemical vapor deposition (MOCVD); chromium carbide; kinetic modeling; numerical simulations; inner-wall coatings; protective coatings

\section{Introduction}

During their working lifetime, tools and machinery components are subjected to intensive degradation due to the combination of abrasive wear, corrosion and oxidation. Because of its hardness and high temperature stability, chromium carbide thin films $\left(\mathrm{CrC}_{x}\right)$ are suitable to increase the performance and extend the lifetime of metallic alloys. Cr-based hard coatings are mainly deposited by physical vapor deposition (PVD) [1], chemical vapor deposition (CVD) [2] or thermo-reactive deposition (TRD) [3]. CVD is considered an effective process to apply thin protective layers because of its ability 
to conformally coat complex geometries and its relative ease of control of the growth rate and the microstructure $[4,5]$. Furthermore, the use of metalorganic compounds as precursors in metalorganic chemical vapor deposition process (MOCVD) has several advantages: (i) reducing the processing temperature needed to avoid structural and dimensional changes of the substrate; (ii) lowering toxicity and corrosive properties when compared to hydrides or chlorides precursors; (iii) benefiting from a wide choice of metalorganic compounds, which make it possible to deposit specific phases that cannot be grown by other techniques; and (iv) for energy saving in a large-scale process.

The protection of the inner walls of long metallic tubes can improve their lifetime in applications where their internal surface is exposed to corrosive, oxidative and abrasive environments as in oil, gas, chemical and nuclear industries where piping delivers corrosive materials or are implemented in extreme environments. Coatings for long and narrow channels like plate heat exchangers [6] or clad tubes in the nuclear industry can be optimized in terms of, microstructure, growth rate and thickness uniformity.

There are at least two technical difficulties that must be overcome to deposit a protective coating with uniform thickness on the inner walls of long tubes exhibiting a high aspect ratio (AR $=L / \mathrm{ID}>100$ ) as piping: (i) the great length $(L)$ to be covered and (ii) the small internal diameter (ID) of the tubes. In the case of long straight tubes, the first issue can be solved by a continuous deposition process with displacement of the tube, or of the deposition zone, on the basis of known methods. For instance, many in-line or roll-to-roll CVD reactors were described to coat $C$ fibers moving at constant speed with $\mathrm{BN}[7,8]$ and $\mathrm{W}$ filaments with $\mathrm{TaC}[9]$, or for continuous deposition of functional layers on flexible substrates as $\mathrm{Nb}_{3} \mathrm{Ge}$ [10] or more recently graphene [11]. These continuous CVD processes in belt furnaces were extended to mass production of many others thin films as $\mathrm{ZnO}$ [12] and are even implemented for photovoltaic $\mathrm{Si}$ at an industrial level [13]. Some of these techniques could be adapted for long straight tubes.

Regarding the inner diameter of tubes, when it is sufficiently large, deposition methods other than CVD can be used. For instance, for diameter larger than $3.5 \mathrm{~cm}$ a hollow cathode plasma immersion ion process can be used as demonstrated for DLC-Si composite coating in 304 stainless steel pipe, but this demonstration was made only over a length of $30 \mathrm{~cm}$ [14]. Modeling and optimization of chemical vapor infiltration (CVI) on the internal surface of porous preforms was a fundamental basis for producing CVD parts for heat-exchanger tubes but the sample reported had a large diameter $(10 \mathrm{~cm})$ for only $45 \mathrm{~cm}$ long, which allowed the use of a central, concentric reactant injector fixed along the tube [15]. Also, a fundamental approach was reported for $\mathrm{CVD}$ of $\mathrm{Si}_{3} \mathrm{~N}_{4}$ tube-shaped substrates with a low AR (12 mm ID) [16]. For smaller diameters and longer tubes, it is still a challenge and CVD techniques are certainly the most appropriate processes for the growth of relatively thick and uniform coatings.

For millimeter ID and lengths greater than one meter a dynamic set-up, i.e., continuous CVD coupled to the displacement of the deposition zone, seems to be a good solution. Thus, after preliminary runs under stationary conditions [17], TiN films were deposited on the inner wall of long steel tubes by moving the furnace [18]. Also by moving the heating system, $\mathrm{SiC}$ thick coatings were grown by continuous CVD on the inner wall of a silica tube [19], Cu was grown by MOCVD on the inner surface of a hollow substrate [20] and $\mathrm{Cr}_{2} \mathrm{O}_{3}$ was deposited inside a zircaloy tube $8 \mathrm{~mm}$ ID by MOCVD [21]. $\mathrm{VC}$ was deposited on the interior surface of steel tubes by moving simultaneously the reactant gas inlet device and the heated zone produced by an radio-frequency (RF) coil [22]. However, for the growth of coatings of a few micrometers thick continuous CVD requires very high growth rates because the substrate is moved at a constant speed across the reaction zone. Also, contamination of the coating by solid by-products deposited in low-temperature zones can have dramatic effects on adhesion [17]. Furthermore, it is necessary to control the movement systems as a conveyor or reels, which increases the cost of the process.

If we exclude vapor deposition techniques with displacement, ALD (Atomic Layer Deposition) processes can be considered because they are well known to conformally coat complex shapes. Thus, 
a theoretical study of ALD of Al thin films on inner wall of rectangular pipe with AR $=50$ was reported [23]. However, this modeling has not been confirmed experimentally and the aspect ratio considered was too low to respond to larger needs in piping. Recently corrosion mitigation coatings were deposited by ALD on the interior surface in a complex cooling circuit [24]. However, ALD is essentially adapted to the growth of metal oxides and it still suffers from very low growth rates, which is problematic for developing protective coatings about $10 \mu \mathrm{m}$ thick.

In stationary conditions, i.e., without moving the reaction zone, CVD coatings grown on inner walls of tubes under isothermal conditions exhibit a maximum thickness near the inlet, then a continuous decrease of the thickness occurs due to depletion of the reactive gas phase. For lengths shorter than a few tens of centimeters, CVD conditions can be found experimentally to obtain a satisfactory uniformity of the thickness along the tube as shown for CNT layers grown inside stainless tubes $40 \mathrm{~cm}$ long [25] and for $\mathrm{SiC}_{x} \mathrm{O}_{y}$ films deposited inside quartz tubes about $60 \mathrm{~cm}$ long (8 $\mathrm{mm} \mathrm{ID)} \mathrm{[26].} \mathrm{However,} \mathrm{these}$ lengths are generally not sufficient for applications. For instance, protective coating on the inner surface of nuclear fuel claddings requires uniformity of thickness over a length of about $4 \mathrm{~m}$. For this application, in the 1980s, Cr coatings as oxygen getter [27] and boron-containing coatings as neutron absorber [28] were deposited by atmospheric pressure CVD inside sections of cladding tubes about $30 \mathrm{~cm}$ long. We have now learned from the modeling and optimization of such processes that low pressure is required to improve uniformity in the axis of the tube. For instance, this was demonstrated by the recent kinetic modeling of Ta CVD in long narrow channels with a high aspect ratio $(\mathrm{AR}=500)[6]$.

This paper presents the growth of $\mathrm{CrC}_{x}$ thin films using a MOCVD process coupled with direct-pulsed liquid injection (DLI) of the precursor [29]. Experimental results relating to morphology, microstructure and composition are presented to introduce the coating challenge in long and narrow tubes. A parametric study has been carried out to describe the influence of operating conditions on coating uniformity inside tubes as long as $1 \mathrm{~m}$ and as narrow as $8 \mathrm{~mm}$ ID. A kinetic growth model adapted to this large-scale process has been developed and simulations were used to validate the model and design upscaling. The rate and efficiency of the process are strongly dependent on reaction kinetics, fluid flow, heat transfer and mass transport in the reaction zone. An in-depth understanding of such reaction-transport phenomena requires computational fluid dynamics (CFD) models that are able to predict growth rate and its uniformity over complex geometries [30-46].

The practical objectives are (i) to identify operating conditions leading to the growth of uniform films over the interior of long tubes and (ii) to predict the spatial distribution of gas-phase species along the tube, which is inherently difficult to probe by in situ non-intrusive techniques.

\section{Experimental Procedure}

The schematic representation of the reactor is shown in Figure 1 and more details can be found in a previous paper [47]. A hot-wall horizontal reactor equipped with the DLI system from Kemstream Company (Montpellier, France) was used. The precursors, bis(benzene)chromium (BBC, a solid compound) or bis(ethylbenzene)chromium (BEBC, a liquid) dissolved (or diluted) in toluene were injected in a flash vaporization chamber maintained at about $180^{\circ} \mathrm{C}$. The precursor solution in toluene was injected in pulsed mode, typically with a frequency of 10 or $20 \mathrm{~Hz}$ and an opening time of the injector varying from 0.5 to $5 \mathrm{~ms}$ depending on the different CVD runs. The mass flow rate of the precursor is calculated from these operating conditions. These injection conditions were chosen according to our previous work [29] to form a mist of very fine droplets necessary to obtain a flash evaporation in the vaporization chamber. Then, the reactive vapor was transported with a $\mathrm{N}_{2}$ flow rate of $500 \mathrm{sccm}$ and was heated at approximately $180{ }^{\circ} \mathrm{C}$ before entering the deposition chamber to prevent condensation.

The precursor vapor is delivered to the reactor inlet and flow inside long and narrow tubes ( 0.3 to $1 \mathrm{~m}$ ) placed in a resistively heated furnace. Two types of tubes were used: (i) a quartz tube, $0.3 \mathrm{~m}$ long and $24 \mathrm{~mm}$ diameter with a test plate of $20 \mathrm{~cm}$ long (Figure 1b); and (ii) a metallic tube $1 \mathrm{~m}$ long with $8 \mathrm{~mm}$ of diameter. In the first case, thickness measurements were made by cutting samples along $20 \mathrm{~cm}$ 
of the flat test substrate. In the second case, the coating thickness was directly measured on cross-sections of the metallic tube. The composition range of $\mathrm{BBC}$ in the carrier nitrogen gas varied from $0.1 \%$ to $0.6 \%$, the reactor pressure range was from $7 \times 10^{2}$ to $7 \times 10^{3} \mathrm{~Pa}$, and the temperature range of the substrate was from 400 to $550{ }^{\circ} \mathrm{C}$. The crystal structure of the films was analyzed by X-ray diffraction (XRD). Surface morphology was studied by scanning electron microscopy (SEM). Electron probe microanalysis (EPMA) was used to determine the composition of the films.

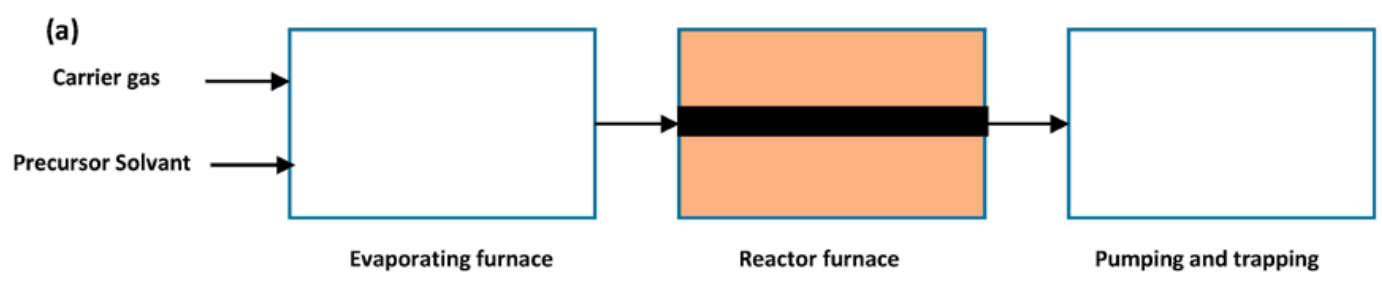

(b)

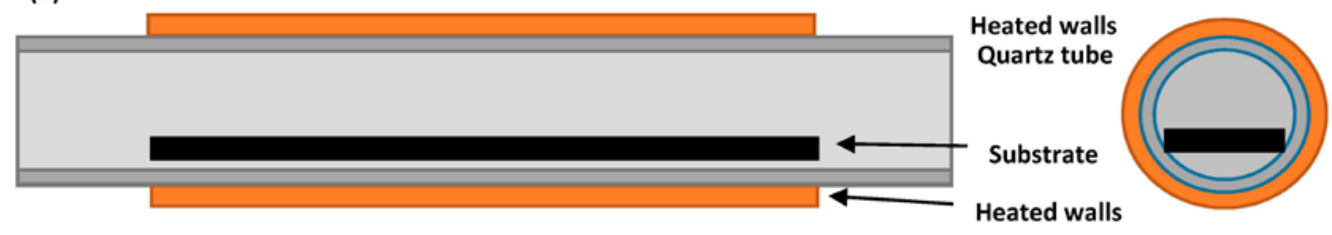

Figure 1. (a) Schematic representation of the direct liquid injection metal-organic chemical vapor deposition reactor (direct-pulsed liquid injection-metalorganic chemical vapor deposition (DLIMOCVD)); the dimensions of the reactor tube are from 0.3 to $1 \mathrm{~m}$; the diameter of the tube is from 8 to $24 \mathrm{~mm}$. (b) Schematic representation of the quartz reactor of $24 \mathrm{~mm}$ in diameter, $30 \mathrm{~cm}$ long, containing a flat substrate of $20 \mathrm{~cm}$.

\section{Experimental Results}

The emerging DLI technique is particularly convenient to feed CVD reactors with high flow rates of precursors exhibiting a poor volatility [47]. Organic solvents are commonly employed to solubilize solid metalorganic compounds or adjust the properties of liquids such as viscosity. It was shown in previous studies $[29,47]$ that an adequate oxygen-free solvent, taking into account reactivity, toxicity, cost, commercial availability and safety, is toluene $\left(\mathrm{C}_{6} \mathrm{H}_{5} \mathrm{CH}_{3}\right)$. This solvent belongs to the same family as the ligands of the precursor and it does not react with it. Furthermore, the corresponding saturation concentration is high enough to deliver high flow rates of the precursor.

All $\mathrm{CrC}_{x}$ coatings deposited inside tubes in the 350-525 ${ }^{\circ} \mathrm{C}$ temperature range and $1.3 \times 10^{2}$ to $7 \times 10^{3}$ Pa pressure range are amorphous. They are dense, with no apparent texture (Figure 2). They have a metallic glossy appearance and a mirror-like surface morphology. In the temperature and pressure ranges under investigation, they exhibit a constant stoichiometry with a ratio $\mathrm{Cr}: \mathrm{C}$ of 2:1, which is intermediate between $\mathrm{Cr}_{7} \mathrm{C}_{3}$ and $\mathrm{Cr}_{3} \mathrm{C}_{2}$. They always contain small amounts of oxygen $(<3$ at. \%). More details can be found in previous works of the authors [29].

The deposition rate varies along the length of the substrate (Figure 1b) due to precursor depletion (Figure 3). In typical conditions, for tubes of $30 \mathrm{~mm}$ in diameter, the maximum growth rate is around $1.6 \mu \mathrm{m} \cdot \mathrm{h}^{-1}$ for a temperature of $450{ }^{\circ} \mathrm{C}$ and a pressure of $7 \times 10^{3} \mathrm{~Pa}$. At the entrance and in the first centimeters, the growth rate increases due to the combined effects of the reactive flow and temperature fields. Then, it rapidly decreases due to depletion of the precursor. When the pressure is decreased to $7 \times 10^{2} \mathrm{~Pa}$, the deposition rate decreases but is more homogeneous along the tube.

This overview of the main characteristics of $\mathrm{CrC}_{x}$ coatings deposited inside tubes introduces the challenge that must be solved: a homogeneous deposition along long $(1 \mathrm{~m})$ and narrow $(8 \mathrm{~mm})$ tube. The next section is devoted to multicomponent mass transport modeling and focused experiments to design the best operating conditions leading to the most uniform coating inside long and narrow tubes. 


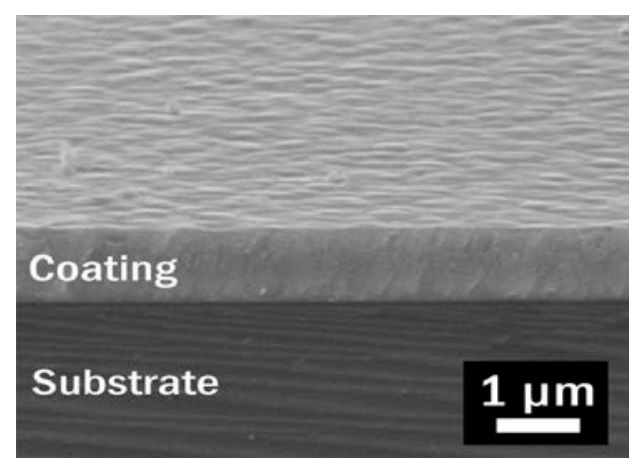

Figure 2. Typical cross section of $\mathrm{Cr}_{x} \mathrm{C}_{y}$ coating grown on silicon substrate placed on the substrate holder inside a quartz tube $30 \mathrm{~cm}$ long, $24 \mathrm{~mm}$ internal diameter (ID) $\left(450{ }^{\circ} \mathrm{C}, 7 \times 10^{3} \mathrm{~Pa}, 500 \mathrm{sccm} \mathrm{N}\right.$, 250 sccm $\mathrm{C}_{7} \mathrm{H}_{8}, 0.8 \mathrm{sccm}$ bis(benzene)chromium (BBC)).

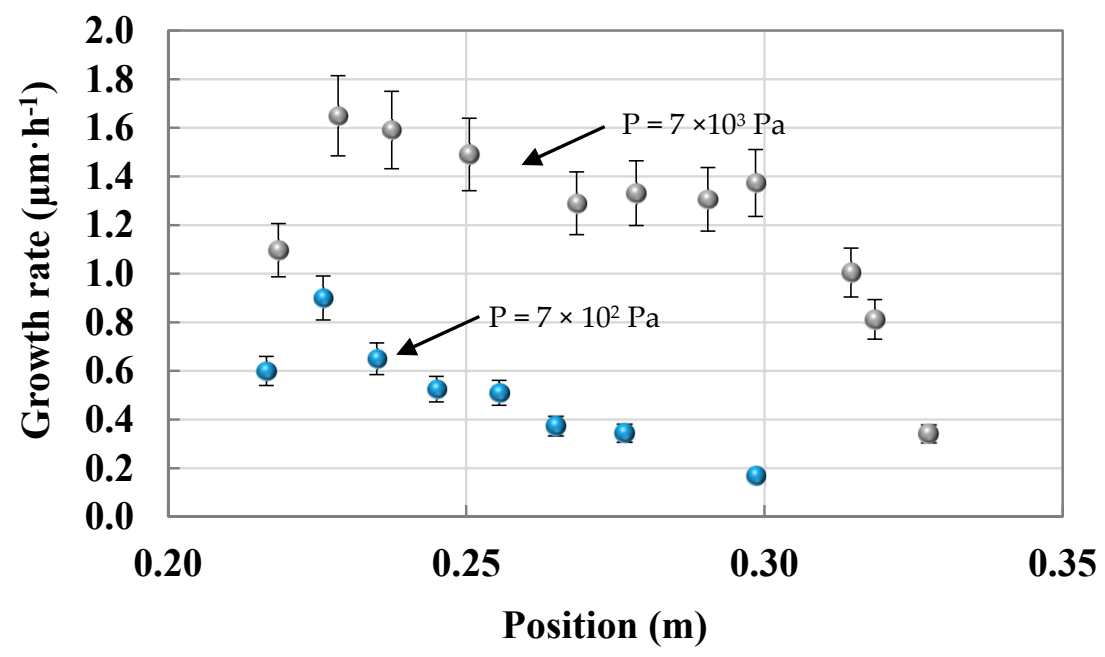

Figure 3. Evolution of the growth rate along the $20 \mathrm{~cm}$ substrate placed in the tube ( $30 \mathrm{~mm}$ in diameter) for two different pressures: Same experimental conditions as in Figure 2 for temperature and $\mathrm{N}_{2}$ flow rate; $\mathrm{BBC}$ flow rate is 0.8 and $3 \mathrm{sccm}(0.16 \%$ and $0.6 \%)$.

\section{Transport Modeling and Databases}

\subsection{Equations}

The governing equations describing flow dynamics, heat transfer and mass transport include continuity, momentum, energy and species balance.

Continuity

$$
\nabla \cdot \rho \vec{v}=0
$$

Momentum balance

$$
\begin{gathered}
\nabla \cdot(\rho \vec{v} \vec{v})=\nabla \cdot \underline{\underline{\tau}}-\nabla P+\rho \vec{g} \\
\underline{\underline{\tau}}=\mu\left(\nabla \vec{v}+(\nabla \vec{v})^{t}\right)-\frac{2}{3} \mu(\nabla \cdot \vec{v}) \cdot \underline{\underline{I}}
\end{gathered}
$$


Energy balance

$$
\begin{aligned}
& c_{p} \nabla \cdot(\rho \vec{v} T)=\nabla \cdot(\lambda \nabla T)+\nabla \cdot\left(R T \sum_{i=1}^{N} \frac{D_{i}^{T}}{M_{i}} \frac{\nabla x_{i}}{x_{i}}\right) \\
& +\sum_{i=1}^{N} \frac{H_{i}}{M_{i}} \nabla \cdot \vec{J}_{i}-\sum_{i=1}^{N} \sum_{k=1}^{K} H_{i} v_{i k}\left(R_{k}^{g}-R_{-k}^{g}\right) i=1, N
\end{aligned}
$$

Species transport

$$
\begin{gathered}
\nabla \cdot\left(\rho \vec{v} \omega_{i}\right)=-\nabla \cdot \vec{J}_{i}+M_{i} \sum_{k=1}^{K} v_{i k}\left(R_{k}^{g}-R_{-k}^{g}\right) i=1, N \\
\vec{J}_{i}^{c}=-\sum_{j=1}^{N}\left(\rho D_{i j}\right) \nabla x_{j} i=1, N \\
\vec{J}_{i}^{T}=-D_{i}^{T} \frac{\nabla T}{T} i=1, N
\end{gathered}
$$

Ideal gas law

$$
\rho=\frac{P M}{R T}
$$

Deposition rate

$$
R_{s i}=\vec{J}_{i} \cdot \vec{n}=\vec{J}_{i}^{c} \cdot \vec{n}+\vec{J}_{i}^{T} \cdot \vec{n} i=1, N
$$

Governing equations where $\rho, \mu, \lambda, c_{p}$ are the density, viscosity, thermal conductivity and specific heat of the gas mixture, $\vec{g}$ the gravity vector, $P$ the pressure, $\vec{v}$ the velocity, $T$ the gas temperature, $\omega_{i}$ the mass fraction of specie $i, x_{i}$ the mole fraction of specie $i, D_{i}^{T}$ its thermal diffusion coefficient, $H_{i}$ its enthalpy, $v_{i k}$ its stoichiometric coefficient in gas phase reaction $k, D_{i j}$ the matrix of diffusion coefficients for $N$ species, $R_{k}^{g}$ the reaction rate of that reaction, $R_{s i}$ the deposition rate of specie $i, R$ the universal gas constant and $M$ the molar mass of the mixture.

The flow is laminar, obeys the ideal gas law, and steady-state conditions prevails [48]. Precursor vapors are very diluted in the carried gas and solvent vapor (more than $99 \%$ of the gaseous phase) so values of the transport properties can be calculated by the kinetic theory of dilute gas $[48,49]$. The boundary conditions for velocity, temperature and species concentration are the following: The temperature and concentration distribution are uniform at the inlet of the tube. On reactive surfaces, Equation (6) is applied for the deposition rate. The temperature of the reactor walls is specified from measurements. All simulations were performed using the CFD-ACE software package (ESI Group, Paris, France).

The properties of the individual species and binary diffusion coefficients have been estimated using gas kinetic theory [48,49] (Section 4.4). Thermodynamic data were evaluated and discussed (Section 4.4). Homogeneous reactions $R_{k}^{g}$ have been evaluated and discussed in the form of an Arrhenius law (Section 4.3):

$$
k_{k}=a_{k} T^{\beta_{k}} \exp \left(\frac{-E_{a k}}{R T}\right)
$$

where $k_{k}$ is the kinetic constant of reaction $k, \beta_{k}$ the temperature exponent, and $E_{a k}$ the activation energy of reaction $k$.

Surface reactions have been evaluated and discussed by using reactive sticking coefficients for monomolecular reactions (Section 4.3). The sticking coefficient ( $S c_{i}$ for species $i$ ) is the fraction of molecules incorporated into the film upon collision with the surface and the deposition rate $R_{s i}$ of specie $i$ is:

$$
R_{s i}=\rho S c_{i} \sqrt{\frac{R T}{2 \pi M_{i}}} \omega_{i}
$$


with such a database, it will be possible for any engineer to compute velocity, temperature and concentration fields, and deposition rate in the range of operating conditions that are investigated.

\subsection{Kinetic Pathways: Study of the Solvent}

Thermal decomposition of bis(arene) $\mathrm{Cr}$ molecules like $\mathrm{Cr}\left(\mathrm{C}_{6} \mathrm{H}_{6}\right)_{2}(\mathrm{BBC})$ and $\mathrm{Cr}\left(\mathrm{C}_{6} \mathrm{H}_{5} \mathrm{C}_{2} \mathrm{H}_{5}\right)_{2}$ (BEBC) occurs in the $350-550{ }^{\circ} \mathrm{C}$ range to yield chromium carbide films. Toluene $\left(\mathrm{C}_{6} \mathrm{H}_{5} \mathrm{CH}_{3}\right)$ is the solvent. On-line mass spectrometry analysis had shown that benzene (83 mol. \%), hydrogen (11 mol. \%) and traces of other hydrocarbons ( $6 \mathrm{~mol}$. \%) were the major gaseous byproducts formed during MOCVD using BBC [50]. Other works on bis(arene)Cr compounds have confirmed that aromatic hydrocarbons and hydrogen originating from the ligands are the main gaseous by-products.

The thermal decomposition of various solvent including aromatic compounds has been studied under conditions comparable to those applied for the growth of the coatings. Experiments under low pressure involving only a flow of toluene diluted in $\mathrm{N}_{2}$ as carrier gas have shown that the solvent decomposition occurs at temperatures higher than $600{ }^{\circ} \mathrm{C}$ (Figure 4) while its decomposition have been predicted by thermodynamic simulation at equilibrium [29]. Indeed, quartz samples were placed in the reactor during the pyrolysis of pure toluene vapor at different temperatures. When the temperature increases, the decomposition of toluene leads to a thin film of carbon giving a light gray tint to the sample, which became darker and darker as the pyrolytic-C film thickness increased. This result is illustrated in Figure 4 by the increase of absorption in the visible range. At temperatures lower than $600{ }^{\circ} \mathrm{C}$, the transmittance of the sample is the same as the bare quartz sample. Therefore, benzene $\left(\mathrm{C}_{6} \mathrm{H}_{6}\right)$, ethylbenzene $\left(\mathrm{C}_{6} \mathrm{H}_{5} \mathrm{C}_{2} \mathrm{H}_{5}\right)$ and toluene $\left(\mathrm{C}_{6} \mathrm{H}_{5} \mathrm{CH}_{3}\right)$ are not decomposed under $600{ }^{\circ} \mathrm{C}$, i.e., in the DLI-MOCVD of this work. The simulation of kinetic pathways of toluene decomposition proposed by Brioukov et al. [50] gives the same conclusions.

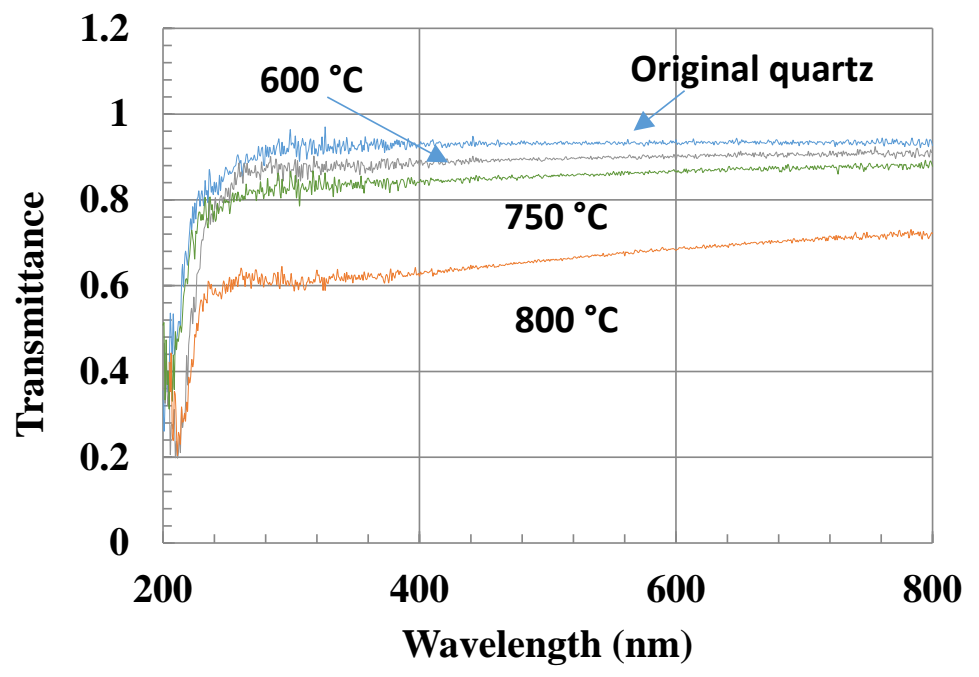

Figure 4. Transmittance spectrum of a bare quartz sample compared to C-coated quartz samples after $1 \mathrm{~h}$ flow of toluene at 600,750 and $800^{\circ} \mathrm{C}$ showing an increase of the absorption in the visible range resulting from the growth of the $\mathrm{C}$ thin film.

At this stage, the first conclusion for the development of the kinetic model is that toluene, used as a solvent for the dilution of $\mathrm{BBC}$ in the injector, and benzene, the ligand of $\mathrm{BBC}$ released as the main reaction byproduct of deposition [51], are thermally stable molecules in the gas phase.

\subsection{Kinetic Pathways: Study of the Reactions}

The average metal-ligand bond energy of bis(arene)chromium (about $160 \mathrm{~kJ} \cdot \mathrm{mol}^{-1}$ ) is significantly lower than that of $\mathrm{C}-\mathrm{C}$ bonds (about $500 \mathrm{~kJ} \cdot \mathrm{mol}^{-1}$ ) and $\mathrm{C}-\mathrm{H}$ bonds (about $450 \mathrm{~kJ} \cdot \mathrm{mol}^{-1}$ ) $[52,53]$. For 
bis(arene)chromium (BBC and $\mathrm{BEBC}$ ), the dissociation energy of the metal-ligand bonds determines the efficiency of the process [51]. It is worth mentioning how difficult it is to resolve the decomposition mechanism at the level of elementary steps under actual growth conditions: high temperatures make intermediates very difficult to identify and, often, only the rate constants for the overall process can be measured [54].

It is assumed that there is a unimolecular reaction in the gas phase involving one Cr-benzene bond breaking followed by surface reactions leading to solid $\mathrm{Cr}$ and $\mathrm{C}$ incorporated into the growing coating (Table 1). The benzene released in the gas phase by Reaction (1) was shown to be non-reactive and is evacuated to the outlet without participating in the deposition reaction. Both the intermediate species mono(benzene)chromium $\mathrm{MBC}\left(\mathrm{CrC}_{6} \mathrm{H}_{6}(\mathrm{~g})\right)$ and $\mathrm{BBC}$ react on surface chromium sites to give bulk $\mathrm{Cr}$ and adsorbed benzene (Reactions (2) and (5), respectively). The gaseous nutrient species $\mathrm{MBC}$ is assumed to immediately decompose upon contact with the hot surface sites (dissociative adsorption) and incorporate $\mathrm{Cr}$ into the film (Reaction (2)). This is a reasonable assumption for this kind of transient species and agrees well with dissociative adsorption on metal surfaces.

Table 1. Reaction pathways. $\mathrm{Cr}(\mathrm{s})$ is a chromium site, $\mathrm{Cr}(\mathrm{b})$ and $\mathrm{C}(\mathrm{b})$ are bulk chromium and carbon respectively, and $\mathrm{C}_{6} \mathrm{H}_{6}(\mathrm{~s})$ is adsorbed benzene.

\begin{tabular}{|c|c|}
\hline No. & Reactions \\
\hline$(1)$ & $\mathrm{Cr}\left(\mathrm{C}_{6} \mathrm{H}_{6}\right)_{2}(\mathrm{~g}) \rightarrow \mathrm{CrC}_{6} \mathrm{H}_{6}(\mathrm{~g})+\mathrm{C}_{6} \mathrm{H}_{6}(\mathrm{~g})$ \\
\hline$(2)$ & $\mathrm{CrC}_{6} \mathrm{H}_{6}(\mathrm{~g})+\mathrm{Cr}(\mathrm{s}) \rightarrow \mathrm{Cr}(\mathrm{b})+\mathrm{C}_{6} \mathrm{H}_{6}(\mathrm{~s})+\mathrm{Cr}(\mathrm{s})$ \\
\hline$(3)$ & $\mathrm{C}_{6} \mathrm{H}_{6}(\mathrm{~s}) \rightarrow 6 \mathrm{C}(\mathrm{b})+3 \mathrm{H}_{2}(\mathrm{~g})$ \\
\hline$(4)$ & $\mathrm{C}_{6} \mathrm{H}_{6}(\mathrm{~s}) \rightarrow \mathrm{C}_{6} \mathrm{H}_{6}(\mathrm{~g})$ \\
\hline$(5)$ & $\mathrm{Cr}\left(\mathrm{C}_{6} \mathrm{H}_{6}\right)_{2}(\mathrm{~g})+\mathrm{Cr}(\mathrm{s}) \rightarrow \mathrm{Cr}(\mathrm{b})+\mathrm{CrC}_{6} \mathrm{H}_{6}(\mathrm{~s})+\mathrm{C}_{6} \mathrm{H}_{6}(\mathrm{~s})$ \\
\hline$(6)$ & $\mathrm{Cr}\left(\mathrm{C}_{6} \mathrm{H}_{6}\right)(\mathrm{s})+\mathrm{Cr}(\mathrm{s}) \rightarrow \mathrm{Cr}(\mathrm{b})+\mathrm{C}_{6} \mathrm{H}_{6}(\mathrm{~s})+\mathrm{Cr}(\mathrm{s})$ \\
\hline
\end{tabular}

A part of absorbed benzene leads to carbon deposition (Reaction (3)) and the other part is desorbed and evacuated in the gas phase (Reaction (4)). Gas-surface reactions describing the interactions of gas-phase species containing $\mathrm{Cr}$ and $\mathrm{C}$ with the growing surface are reactions 2-6. Benzene decomposes on the surface through a catalytic pathway that lowers the activation barrier for its decomposition [55]. It was proposed that benzene decomposition on the metallic surface occurs by decyclotrimerization initiated by $\mathrm{C}-\mathrm{C}$ bond fission and that acetylenic species are intermediates during the process. Maury et al. [51] have already shown that benzene represents $98 \%$ of the gas exhaust. MBC was never isolated because of the short lifetime of this intermediate. However the existence of neutral MBC molecule is supported by DFT calculations with a $\mathrm{Cr}-\mathrm{C}_{6} \mathrm{H}_{6}$ bond energy of about $35 \mathrm{~kJ} \cdot \mathrm{mol}^{-1}$ [33] and experiments of laser vaporization in the gas phase [56]. Gas-surface interactions are assumed to occur with a reactive sticking coefficient equal to unity and no activation barriers or steric effects. The growth rate estimated by this approach is the maximum possible and is only limited by the arrival of gas-phase species to the surface. For surface chemistry modeling, a maximum density of surface sites of $10^{-9} \mathrm{~mol} \cdot \mathrm{cm}^{-2}$ was assumed based on the density of amorphous $\mathrm{CrC}_{x}$ films.

Finally, the reaction mechanism retained has been reduced to the 6 reactions in Table 1 (one homogenous and 5 surface reactions). Initially other elementary reactions (13 in total) were considered then discarded. For example, in terms of homogeneous phase reactions, a second gas phase reaction corresponding to the homogeneous decomposition of $\mathrm{MBC}$, which would release the second benzene ligand, was not retained because it should lead to homogeneous nucleation of the $\mathrm{Cr}$ atoms in the gas phase, and thus to the formation of metal powder, which was not experimentally observed. The end of the $\mathrm{CrC}_{x}$ deposition occured at the outlet of the CVD reactor abruptly when the temperature is lower than $250{ }^{\circ} \mathrm{C}$, without condensation of solid byproducts. Also, the possible reaction between the $\mathrm{Cr}$ atoms formed in this hypothetical second homogeneous reaction and the molecules of benzene (ligand) or toluene (solvent) was not kept. Indeed, such a reaction is known and used to produce pure 
bis(arene)chromium by direct synthesis but under conditions very different from those of the MOCVD reactor [57].

About gas-surface reactions, the non-dissociative adsorption of $\mathrm{MBC}$ was not retained because the low bond energy of $\mathrm{Cr}-\mathrm{C}_{6} \mathrm{H}_{6}\left(35 \mathrm{~kJ} \cdot \mathrm{mol}^{-1}\right)$ [53] makes this reaction unlikely with regard to dissociative adsorption of $\mathrm{MBC}$ on a $\mathrm{Cr}$ site (Reaction (2)). Also, the non-dissociative adsorption of BBC on $\mathrm{Cr}$ sites is an unlikely reaction since the surface species that would be produced would certainly be less stable than BBC itself, which is supposed to be readily decomposed in the gas phase according to reaction 1. Even if $\mathrm{BBC}$ was not completely dissociated in the gas phase by forming $\mathrm{MBC}$, it was previously found to dissociate on the $\mathrm{Ni}(100)$ surface at temperature as low as $47^{\circ} \mathrm{C}$ [58], and so its non-dissociative adsorption is unlikely. However the surface species formed by non-dissociative adsorption of BBC would not be fictitious because this should occur by $\pi$-electron transfer from the aromatic ring to a $\mathrm{Cr}$ site, which would lead to a sandwich structure similar to that of the Decker complexes (arene) $\mathrm{Cr}$ (arene) $\mathrm{Cr}$ (arene) which are less stable than the parent sandwich molecule $\mathrm{Cr}$ (arene $)_{2}$ [59]. As a result, only the dissociative adsorption of BBC could be considered at this stage with the related Reactions (5) and subsequently (6).

The surface decomposition of toluene (solvent) molecules, and possibly benzene released by Reaction (1), was neglected. Indeed, it was demonstrated in the previous section that toluene is not decomposed in the gas phase below $600{ }^{\circ} \mathrm{C}$ under low-pressure DLI-MOCVD conditions. Furthermore, in order for the surface decomposition of toluene (or benzene) to be significant, its adsorption on $\mathrm{Cr}$ sites should first be considered. However the surface decomposition of toluene (or benzene) is in competition with its desorption (Reaction (4)) and it has been shown that the benzene desorption on $\mathrm{Mo}(110)$, a metal of the same column 6 as $\mathrm{Cr}$, was favored because of the greater activation energy of its surface decomposition [60]. Moreover, we have previously shown that the $\mathrm{C}$ content of the coatings was almost the same using $\mathrm{Cr}\left(\mathrm{C}_{6} \mathrm{H}_{6}\right)_{2}$ [5,61-63], $\mathrm{Cr}\left(\mathrm{C}_{6} \mathrm{H}_{5} \mathrm{Pr}\right)_{2}$ [64] or $\mathrm{Cr}\left(\mathrm{C}_{6} \mathrm{H}_{5} \mathrm{C}_{2} \mathrm{H}_{5}\right)_{2}$ [65] as precursor, both with $[29,61,65]$ and without solvent $[5,62-64]$ and both in a cold-wall CVD reactor $[29,61]$ and a hot-wall reactor $[29,62,64,65]$, which is known to favor homogeneous reactions. An obvious conclusion is that the $\mathrm{C}$ incorporated into the film comes from the surface decomposition of the aromatic ring and not from the aliphatic groups linked to the ring. It is, therefore, more likely that the incorporation of $C$ will come from the surface decomposition of aromatic rings already adsorbed on the surface such as those from Reactions (2) and (5). This bis(arene)chromium chemistry involves $\operatorname{Cr}(0)$ compounds and it contrasts with that of tetra-alkylchromium precursors (i.e., $\mathrm{Cr}(\mathrm{IV})$ compounds) for which the film composition varies significantly in a narrow temperature range of deposition because of very different mechanisms involving many transient species, especially in the gas phase [66].

The second conclusion for the development of the kinetic model is that BBC is decomposed in the gas phase to give $\mathrm{MBC}$, which reacts instantaneously on surface sites to give bulk $\mathrm{Cr}$ and $\mathrm{C}$. Also, it is assumed that $\mathrm{BBC}$ and $\mathrm{BEBC}$ undergo the same decomposition mechanism, ethylbenzene being substituted for benzene in the case of BEBC. However, to be able to simulate reactive mass transport, both thermodynamic $\left(C_{\mathrm{p}}, \mathrm{H}\right.$ and $\left.\mathrm{S}\right)$ and transport data (Lennard-Jones parameters) must be evaluated to complete the database.

\subsection{Estimation of Thermodynamic and Transport Data}

The thermodynamic properties of all gaseous species involved, heat capacity, enthalpy and entropy, are needed for the development of the kinetic model. Until now, no thermodynamic data have been reported for gaseous BBC and $\mathrm{MBC}$ precursors. Consequently, to calculate missing information, the JANAF method was employed [67] for the case of non-linear polyatomic species. Indeed, it is possible to obtain the gas phase thermal functions using the molecular structure (bonds lengths and angles), the relative molecular mass, the principal moments of inertia, the symmetry number, the vibrational frequencies and the low-lying electronic levels.

For gaseous BBC, the structure with the symmetry D6h was retained as proposed in the calculations of Schaffer et al. [68] using the infrared spectroscopy measurements of Ngai et al. [69]: 
the benzene ligands in $\mathrm{BBC}(\mathrm{g})$ are slightly more distended than free-benzene molecules having a $\mathrm{C}-\mathrm{C}$ length of $1.423 \AA \pm 0.002 \AA$ instead of $1.399 \AA \pm 0.001 \AA$. For $\mathrm{MBC}(\mathrm{g})$, the same values were taken but only one benzene was considered.

To calculate the principal moment of inertia with Hirschfelder method [70] we have used the interatomic distances given by Haaland et al. [71] having a $\mathrm{Cr}$ in the center of the cartesian projection and the $\mathrm{C}-\mathrm{H}$ oriented $5^{\circ}$ outside of the carbon planar cycle: The calculated products $\mathrm{I}_{\mathrm{A}} \mathrm{I}_{\mathrm{B}} \mathrm{I}_{\mathrm{C}}$ are $5.8055 \times 10^{-112} \mathrm{~kg}^{3} \mathrm{~m}^{6}$ for $\mathrm{BBC}(\mathrm{g})$ and $2.5083 \times 10^{-113} \mathrm{~kg}^{3} \mathrm{~m}^{6}$ for $\mathrm{MBC}(\mathrm{g})$. The vibrational frequencies and the low-lying electronic levels were extracted form infrared data made by Andrews et al. [72]. The calculated thermal functions for $\mathrm{BBC}(\mathrm{g})$ and $\mathrm{MBC}(\mathrm{g})$ are given in the form of NASA polynomials [73,74] in Table 2.

Table 2. Thermodynamic data for $\mathrm{BBC}(\mathrm{g})$ and mono(benzene)chromium $(\mathrm{MBC}(\mathrm{g}))$; $\mathrm{T}$ is the temperature, $R$ the universal gas phase constant, $H$ the enthalpy, $S$ the entropy and $C_{p}$ the specific heat.

\begin{tabular}{|c|c|c|c|c|c|c|c|c|}
\hline Gas & $\begin{array}{l}\text { Temperature } \\
\text { (K) }\end{array}$ & $a_{1}$ & $a_{2}$ & $a_{3}$ & $a_{4}$ & $a_{5}$ & $a_{6}$ & $a_{7}$ \\
\hline $\mathrm{BBC}$ & $298-660$ & $-1.207 \times 10^{1}$ & $1.460 \times 10^{-1}$ & $-1.248 \times 10^{-4}$ & $6.843 \times 10^{-8}$ & $-2.999 \times 10^{-11}$ & $2.805 \times 10^{4}$ & $4.661 \times 10^{1}$ \\
\hline BBC & $660-1000$ & 7.133 & $7.445 \times 10^{-2}$ & $-2.730 \times 10^{-5}$ & $1.095 \times 10^{-17}$ & $-6.776 \times 10^{-21}$ & $2.410 \times 10^{4}$ & $-4.700 \times 10^{1}$ \\
\hline MBC & $770-1000$ & 2.995 & $4.138 \times 10^{-2}$ & $-1.576 \times 10^{-5}$ & $-2.168 \times 10^{-19}$ & 0.000 & $2.809 \times 10^{4}$ & $-1.450 \times 10^{1}$ \\
\hline \multicolumn{9}{|c|}{$\frac{C_{p}(T)}{R}=a_{1}+a_{2} T+a_{3} T^{2}+a_{4} T^{3}+a_{5} T^{4}$} \\
\hline \multicolumn{9}{|c|}{$\frac{H(T)}{R T}=a_{1}+\frac{a_{2}}{2} T+\frac{a_{3}}{3} T^{2}+\frac{a_{4}}{4} T^{3}+\frac{a_{5}}{5} T^{4}+\frac{a_{6}}{T}$} \\
\hline \multicolumn{9}{|c|}{$\frac{S(T)}{R}=a_{1} \ln (T)+a_{2} T+\frac{a_{3}}{2} T^{2}+\frac{a_{4}}{3} T^{3}+\frac{a_{5}}{4} T^{4}+a_{7}$} \\
\hline
\end{tabular}

For the evaluation of transport properties, two input parameters, called the Lennard-Jones parameters, are needed for each gas species: the collision diameter of the molecules and their maximum energy of attraction. Transport data for non-Cr reactants and products were taken from the Chemkin transport database [49]. For Cr-containing species, Lennard-Jones parameters were estimated using the group theory [75]. Diffusivity, conductivity and viscosity of the mixture were calculated from kinetic theory based on Lennard-Jones parameters (Table 3) [48,49].

Table 3. Lennard-Jones parameters for species used in the simulation.

\begin{tabular}{ccc}
\hline Gas Species & Collision Diameter $(\AA)$ & Potential (K) \\
\hline $\mathrm{BBC}$ & 6.98 & 519.2 \\
$\mathrm{MBC}$ & 6.03 & 462.4 \\
$\mathrm{C}_{6} \mathrm{H}_{6}$ & 5.35 & 412.3 \\
$\mathrm{C}_{2} \mathrm{H}_{2}$ & 4.1 & 209 \\
$\mathrm{C}_{7} \mathrm{H}_{8}$ & 5.92 & 410 \\
$\mathrm{H}_{2}$ & 2.92 & 38 \\
$\mathrm{~N}_{2}$ & 3.8 & 71.4 \\
\hline
\end{tabular}

Thermodynamic equilibrium calculations, based on previously estimated data of gas-phase pyrolysis, i.e., without including the solid chemical species in the calculation, show that BBC is dissociated in $\mathrm{C}_{6} \mathrm{H}_{6}$ and $\mathrm{MBC}$ for temperature as low as $200{ }^{\circ} \mathrm{C}$ and it almost completely disappeared at $600{ }^{\circ} \mathrm{C}$. The $\mathrm{MBC}$ species is stable in the range $200-600^{\circ} \mathrm{C}$ and, consequently, could be the major species coming from the homogeneous decomposition of BBC. We can note the good consistency between the theoretical temperature of the beginning of decomposition of the $\mathrm{BBC}$ in the gas phase $\left(200^{\circ} \mathrm{C}\right.$ ) and the experimental temperature of the beginning of the growth (about $250{ }^{\circ} \mathrm{C}$ ). Including solid species in the thermodynamic calculation, the dominant species formed $\operatorname{are~} \mathrm{Cr}_{3} \mathrm{C}_{2}$ and $\mathrm{C}$ as solid phases, and $\mathrm{H}_{2}$ gas with traces of light hydrocarbons as $\mathrm{C}_{2} \mathrm{H}_{4}$. These results give evidence that the deposition process is far from thermodynamic equilibrium: it is controlled by the kinetics. 
After assuming that (i) toluene was not involved in the mechanism; and that (ii) the BBC was decomposed in the gas phase to produce $\mathrm{MBC}$ which reacted instantly on the surface to give bulk $\mathrm{Cr}$ and $\mathrm{C}$; a third conclusion emerges from this section for the development of a simplified kinetic model. This is to assume that the BBC is almost completely decomposed into the gas phase in MBC and benzene at the temperatures used in CVD experiments $\left(400-550{ }^{\circ} \mathrm{C}\right)$ and that its decomposition on the growing surface is negligible. This is supported by its high reactivity. As a result, the two related Reactions (5) and (6) reported in Table 1 can be neglected in the conditions of this study.

\section{Results: Deposition in Long and Narrow Tubes}

\subsection{Preliminary Experiments in Short Tubes}

The first step in modeling reactive mass transport was to fit the activation energy and the pre-exponential factor (Arrhenius law) of Reaction (1) (Table 1) with experiments. The first reactor used was a quartz reactor of $24 \mathrm{~mm}$ of diameter, $30 \mathrm{~cm}$ long containing a flat steel substrate $20 \mathrm{~cm}$ long (Figure $1 \mathrm{~b}$ ), and heated at 450,500 and $550^{\circ} \mathrm{C}$. The flow rate of the carrier gas was $500 \mathrm{sccm}$ and the flow rate of $\mathrm{BBC}$ was going from 0.8 to $3 \mathrm{sccm}$ (Table 4). The fitting was first made with a 2-dimensionnal approximation of the reactor geometry then in $3 \mathrm{D}$, which is representative of the geometry investigated. The temperature profile applied on the outer wall of the tube was the experimental values measured. Figure 5 shows the temperature profile in the 3D reactor. A cold finger at the entrance of the reactor comes from the injection of cold gas $\left(200^{\circ} \mathrm{C}\right)$ through a narrow area. This kind of situation is commonly found in large-scale CVD reactors [76,77].

Table 4. Operating conditions used for modeling.

\begin{tabular}{ccccccc}
\hline $\begin{array}{c}\text { Experiment } \\
\text { (Run) }\end{array}$ & $\begin{array}{c}\text { Temperature } \\
\left({ }^{\circ} \mathbf{C}\right)\end{array}$ & $\begin{array}{c}\text { BBC Flow } \\
(\mathbf{s c c m})\end{array}$ & $\begin{array}{c}\text { Toluene } \\
\text { Flow }(\mathbf{s c c m})\end{array}$ & $\begin{array}{c}\mathbf{N}_{\mathbf{2}} \text { Flow } \\
(\mathbf{s c c m})\end{array}$ & $\boldsymbol{P ( P a )}$ & $\begin{array}{c}\text { Injection } \\
\text { Frequency (Hz) }\end{array}$ \\
\hline 1 & 450 & 0.8 & 220 & 500 & $7 \times 10^{3}$ & 10 \\
2 & 450 & 3 & 630 & 500 & $7 \times 10^{3}$ & 20 \\
3 & 500 & 0.9 & 250 & 500 & $7 \times 10^{3}$ & 10 \\
4 & 500 & 3.2 & 680 & 500 & $7 \times 10^{3}$ & 20 \\
5 & 550 & 0.8 & 230 & 500 & $7 \times 10^{3}$ & 10 \\
6 & 550 & 3.6 & 760 & 500 & $7 \times 10^{3}$ & 20 \\
\hline
\end{tabular}

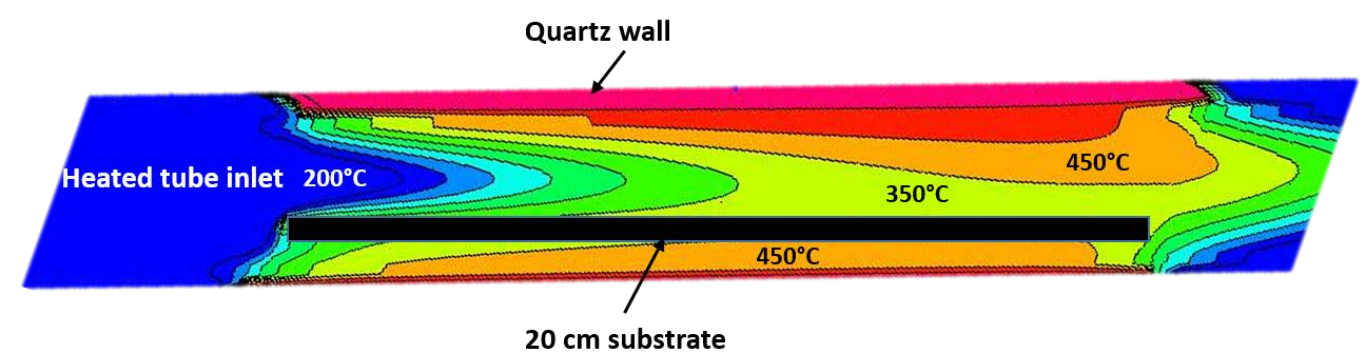

Figure 5. Temperature field in the central $X-Y$ slice of the tubular reactor schematized in Figure $1 b$ (Table 4, Run 1).

The fit of kinetic constants was performed with six different configurations: two injection frequencies (10 and $20 \mathrm{~Hz}$ ) and three deposition temperatures $\left(450,500\right.$ and $550{ }^{\circ} \mathrm{C}$ ). The total pressure was kept constant at $7 \times 10^{3} \mathrm{~Pa}$. It was assumed that: (i) Reaction (1) (Table 1) is the limiting step of the deposition mechanism in agreement with the fact that the bonding energy for dissociating the first ligand is the largest; (ii) $\mathrm{BBC}$ is completely decomposed into $\mathrm{MBC}$ and $\mathrm{C}_{6} \mathrm{H}_{6}$ released in the gas phase (according to thermodynamic simulation in homogeneous gas phase); and (iii) surface reactions are not-limiting, have a sticking coefficient of 1 (Reaction (2)), and conserve the measured stoichiometry 2:1 for the $\mathrm{Cr}$ :C ratio (Reactions (3) and (4)). The best fit found for the activation energy and the pre-exponential 
factor is $A=1.2 \times 10^{9} \mathrm{~s}^{-1}$ and $E=97 \mathrm{~kJ} \cdot \mathrm{mol}^{-1}$. The exponent $\beta$ of temperature in Equation (7) is zero because Reaction (1) is monomolecular [78]. This activation energy is close to the experimental apparent activation energy estimated by Schuster et al. [5]. It is lower than the average value of the energy-bond breaking of the first ligand $\left(160 \mathrm{~kJ} \cdot \mathrm{mol}^{-1}\right)$ but, as is common for metalorganic compounds, the activation barrier for the overall decomposition of BBC is largely influenced by surface reactions and catalytic effects. The magnitude of the pre-exponential constant (frequency factor) is coherent with values found in the literature for monomolecular decomposition [78]. Table 5 summarizes the kinetic model with data that will be applied in further simulations.

Table 5. Kinetic data in the form defined by Equations (7) and (8).

\begin{tabular}{|c|c|c|c|}
\hline Reaction & $A\left(\mathrm{~s}^{-1}\right)$ & $E_{a} / R(\mathrm{~K})$ & SC \\
\hline $\begin{array}{l}\left.\text { (1) } \mathrm{Cr}_{(} \mathrm{C}_{6} \mathrm{H}_{6}\right)_{2}(\mathrm{~g}) \rightarrow \mathrm{CrC}_{6} \mathrm{H}_{6}(\mathrm{~g})+\mathrm{C}_{6} \mathrm{H}_{6}(\mathrm{~g}) \\
\text { (2) } \mathrm{CrC}_{6} \mathrm{H}_{6}(\mathrm{~g})+\mathrm{Cr}(\mathrm{s}) \rightarrow \mathrm{Cr}(\mathrm{b})+\mathrm{C}_{6} \mathrm{H}_{6}(\mathrm{~s}) \\
\text { (3) } \mathrm{C}_{6} \mathrm{H}_{6}(\mathrm{~s}) \rightarrow 6 \mathrm{C}(\mathrm{b})+3 \mathrm{H}_{2}(\mathrm{~g}) \\
\text { (4) } \mathrm{C}_{6} \mathrm{H}_{6}(\mathrm{~s}) \rightarrow \mathrm{C}_{6} \mathrm{H}_{6}(\mathrm{~g})\end{array}$ & $1.2 \times 10^{9}$ & 11,700 & $\begin{array}{c}- \\
1 \\
\text { fitted } \\
\text { fitted }\end{array}$ \\
\hline
\end{tabular}

The increase of the deposition rate at the entrance of the reactor is a competition between the cold finger and the decomposition rate of BBC (Figure 6). After $5 \mathrm{~cm}$ (on the steel plate $20 \mathrm{~cm}$ long), the effect of the depletion of reactive species leads to a rapid decrease of the deposition rate. This kind of profile is common in horizontal CVD reactors [34,40] and its optimization is a complex interaction of flow rate, precursor concentration, temperature and pressure fields and geometry design.

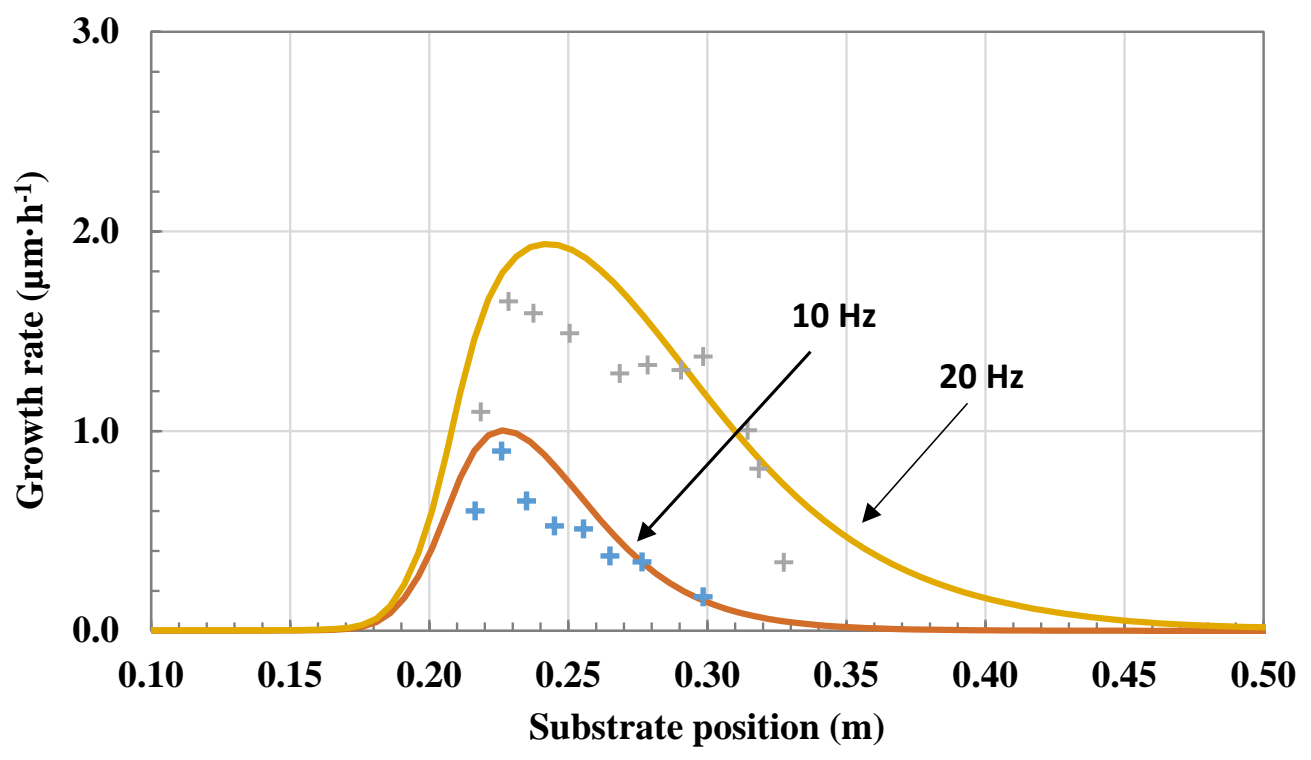

Figure 6. Comparison of calculated $(-)$ and measured (+) growth rate of chromium carbide on the $20 \mathrm{~cm}$ substrate in the conditions of Table 4 (Run 1 and 2).

\subsection{Chemical Vapor Deposition (CVD) Experiments inside Long and Narrow Tubes}

The second step of this modeling approach was to study the deposition directly inside long and narrow tubes. The tubes studied were now directly used as reactors. They were $1 \mathrm{~m}$ long and have an inner diameter of $8 \mathrm{~mm}$. After deposition, the tubes were cut in several slices to measure the thickness of the coating, its structure and morphology. The coating had an amorphous structure and a composition identical to that presented in the previous section and reported in detail elsewhere [65].

The models and databases developed and fitted for the previous short reactor gave results in good agreement with experiments performed in this new reactor geometry (Figure 7). A rapid depletion of 
the precursor downstream led to a poor uniformity along the inner wall of the tube. The conversion yield relative to the precursor was close to $60 \%$ at $450{ }^{\circ} \mathrm{C}$ and $40 \%$ at $400{ }^{\circ} \mathrm{C}$ as determined from the $\mathrm{CrC}_{x}$ mass deposited. This decrease was representative of a thermally activated process. There was a very good agreement with calculated yields. The challenge was to significantly improve both the uniformity of the thickness profile on the internal walls of the tube and the average thickness, which should reach about $10 \mu \mathrm{m}$ for applications. One issue was that CVD parameters often act in an antagonistic way to optimize these two requirements. Extensive simulation was performed to find the best operating conditions in a range of temperature, pressure and precursor composition suitable for industrialization of the process, i.e., low temperature, high thickness uniformity, as well as high growth rate and high conversion rate of the precursor to minimize the cost of the process. A good compromise to fulfil these requirements was calculated for the following conditions: $375^{\circ} \mathrm{C}$, $1.3 \times 10^{2} \mathrm{~Pa}, 4.33 \mathrm{sccm}$ precursor flow rate, $100 \mathrm{sccm}$ toluene flow rate and $500 \mathrm{sccm} \mathrm{N_{2 }}$ flow rate.

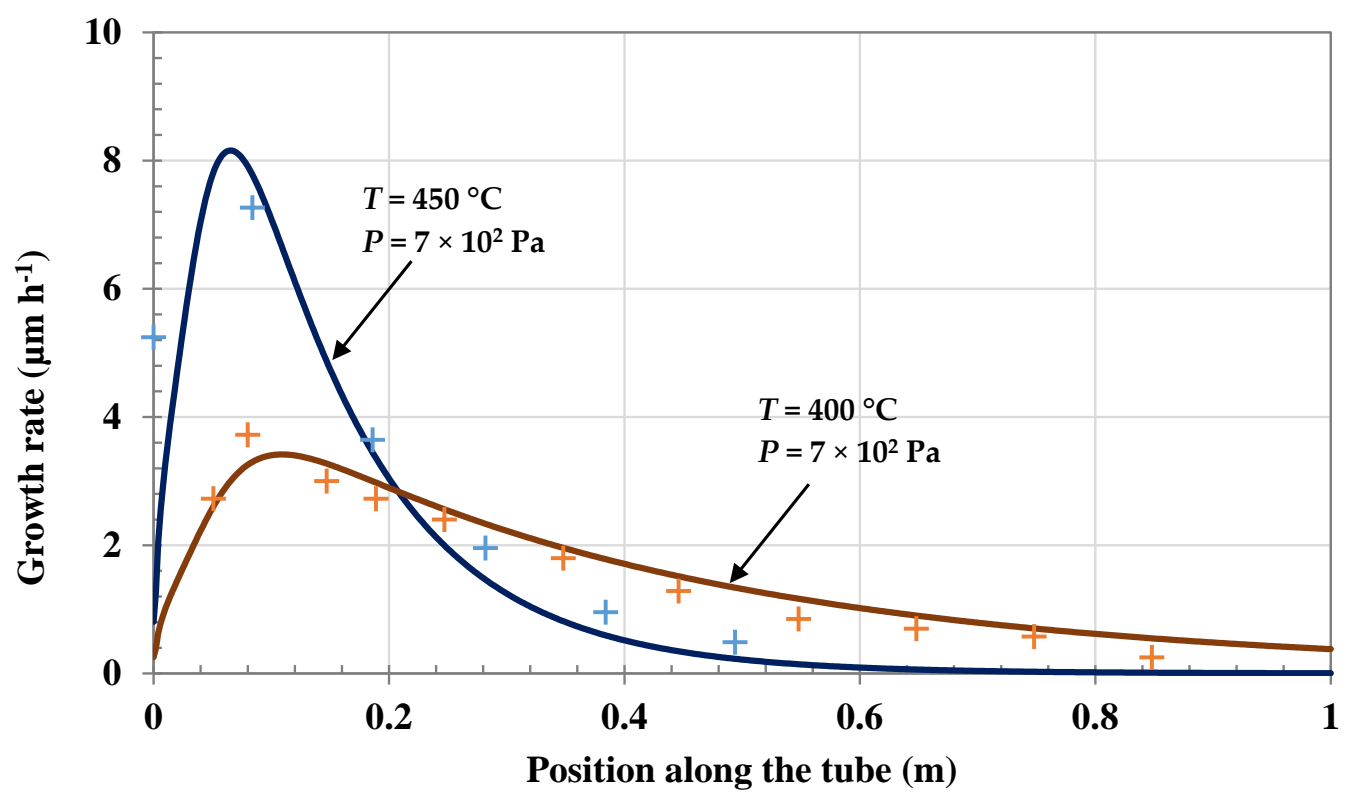

Figure 7. Comparison of calculated (-) and measured (+) growth rate of chromium carbide along the $1 \mathrm{~m}$ reactor walls $\left(T=400\right.$ and $450^{\circ} \mathrm{C}, P=7 \times 10^{2} \mathrm{~Pa}$, precursor flow rate $4.4 \mathrm{sccm}, \mathrm{N}_{2}$ flow rate $500 \mathrm{sccm})$.

A further improvement was simulated both to further optimize the thickness uniformity and to maximize the average thickness. It consisted of injecting the precursor successively and alternately at each end of the reactor tube with long sequences for several minutes to lower the residence time and increase the precursor availability. Under these conditions, the simulated thickness profiles shown in Figure 8 revealed that excellent thickness uniformity can be achieved at low pressure $\left(1.3 \times 10^{2} \mathrm{~Pa}\right)$ and low temperatures $\left(T \leq 400{ }^{\circ} \mathrm{C}\right)$, but at the expense of a lower thickness. The relative variation between maximum and minimum thicknesses was lower than $10 \%$. For higher values of pressure and temperature, a steep increase (or decrease) at the inlet (or outlet) side was found for this type of configuration.

It was not experimentally possible to perform experiments in the best simulated conditions. As a CVD experiment representative of this new concept of successive and alternating feeding at each end, a coating was made in two sequences of equivalent duration $(3 \mathrm{~h})$ where the injection of the precursor was made alternately at each end. The deposition temperature was $400{ }^{\circ} \mathrm{C}$ and the total pressure was $1.3 \times 10^{3} \mathrm{~Pa}$. The total thickness of the coating was the sum of these two sequences. Experimental data were compared to the simulation in Figure 9. Overall, there was a good agreement between the experiment and the simulation, and the uniformity of thickness was quite good for 
a relatively thick protective coating on the inner walls of tubes. The relative variation between the maximum and minimum thickness was about $40 \%$ for experimental data and $37 \%$ for the simulation along the isothermal zone of about $75 \mathrm{~cm}$. With this novel protocol and these growth conditions, the minimum growth rate was about $2.1 \mu \mathrm{m} / \mathrm{h}$ and the conversion yield relative to the precursor was close to $60 \%$, as determined from the $\mathrm{CrC}_{x}$ mass deposited. As for results presented in Figure 7 , there was a very good agreement with calculated yields. These results are very promising for the industrialization of such a process.

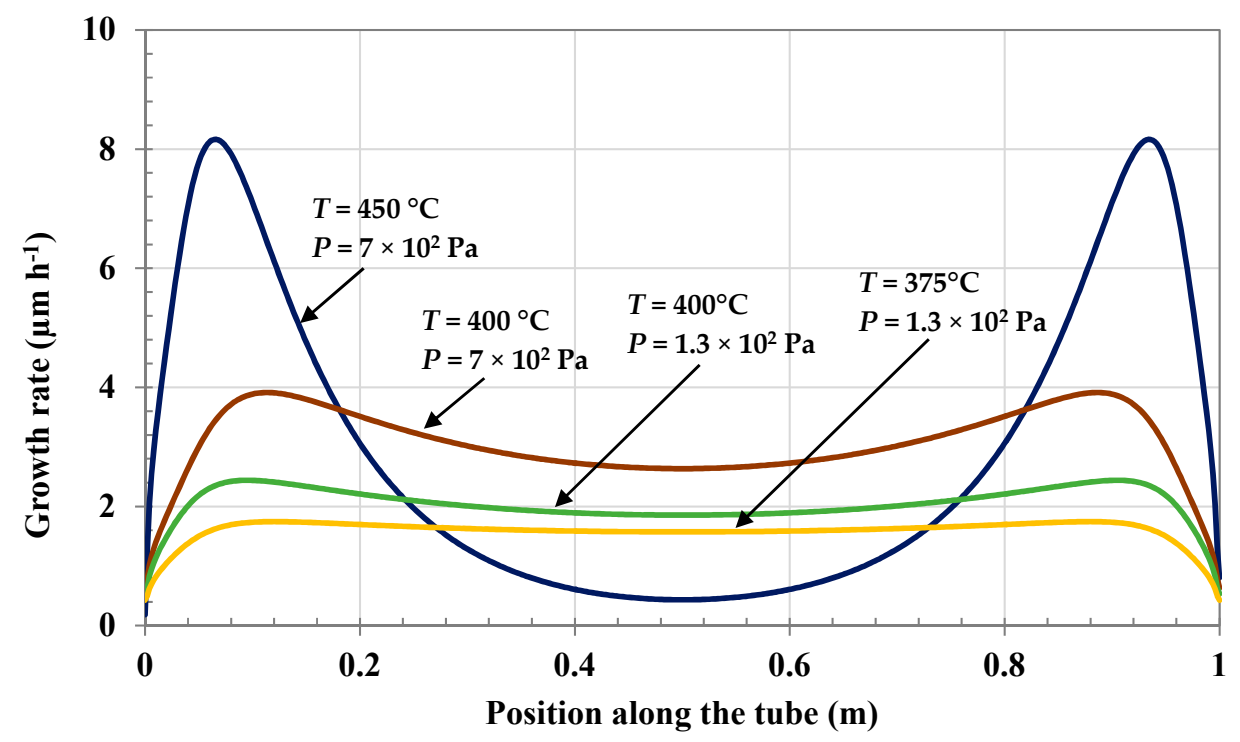

Figure 8. Calculated growth rate of chromium carbide along the $1 \mathrm{~m}$ reactor walls with alternate injection $\left(T=450,400\right.$ and $\left.375^{\circ} \mathrm{C}\right)$.

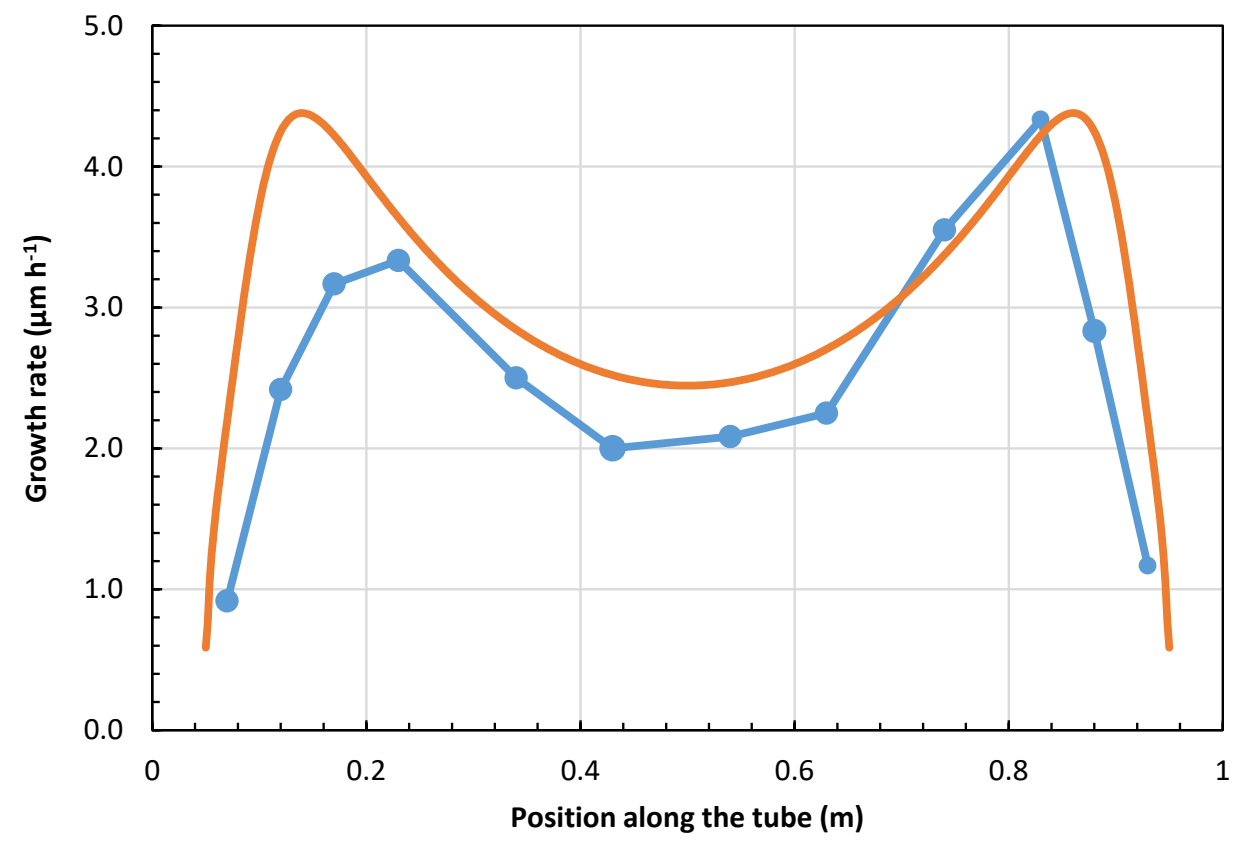

Figure 9. Calculated (-) and experimental $(\bullet)$ growth rate of $\mathrm{CrC}_{x}$ coatings along the inner wall of the tube reactor $1 \mathrm{~m}$ long with the injection of the precursor successively and alternately at each end $\left(T=400{ }^{\circ} \mathrm{C} ; \mathrm{P}=1.3 \times 10^{3} \mathrm{~Pa}\right.$; duration $=2 \times 3 \mathrm{~h} ; 500 \mathrm{sccm} \mathrm{N} \mathrm{N}_{2}$; injection of $0.5 \mathrm{~g} \mathrm{~min}^{-1}$ of precursor solution in toluene containing $10.3 \mathrm{wt}$ \% of bis(ethylbenzene)chromium (BEBC)). 


\section{Conclusions}

The results presented provide robust kinetic and multicomponent transport models capable of predicting amorphous $\mathrm{CrC}_{x}$ growth at a range of low temperature $\left(400\right.$ to $\left.550{ }^{\circ} \mathrm{C}\right)$ and pressures $\left(7 \times 10^{2}\right.$ to $\left.7 \times 10^{3} \mathrm{~Pa}\right)$ well-suited to coat long and narrow metallic tubes. The development of the model is based on previously published data and additional experiments reported here. It allows the validation of the effects of precursor depletion along the inner walls of tubes as a function of the geometry, temperature, pressure and dilution of reactive species. The deposition of amorphous $\mathrm{CrC}_{x}$ coatings from $\mathrm{BBC}$ is correctly described by the initial gas phase decomposition of $\mathrm{BBC}$ in $\mathrm{MBC}$ and benzene involving the bond breaking of the first $\mathrm{Cr}-\mathrm{C}_{6} \mathrm{H}_{6}$ bond. It is followed by adsorption of MBC (and possibly a part of benzene) on surface sites leading to chromium and carbon deposition, and subsequently the formation of chromium carbide. It is also shown that the toluene, used as solvent for the liquid injection of BBC solution, does not participate to the reaction pathways.

Finally, it should be pointed out that the DLI-MOCVD process is capable of depositing rather uniform coatings inside long $(1 \mathrm{~m})$ and narrow $(8 \mathrm{~mm})$ tubes at low temperature to maintain the mechanical integrity of metal alloys. The peculiarities of this chemical system are that it does not form a coating below a temperature threshold of about $250^{\circ} \mathrm{C}$ or solid byproducts condensed on the reactor wall in the low-temperature zones, and the composition and microstructure of the coatings are constant in the temperature range explored.

It follows that we have implemented an innovative concept of successive and alternating feeding of the tube at each end. This original method allows a good optimization of (i) the uniformity of thickness along the tube, (ii) its average growth rate, and (iii) the conversion yield of the precursor, which satisfies the main requirements for the industrialization of this process for inner-wall coating of tubes. $\mathrm{CrC}_{x}$ coatings were successfully deposited by this process on the internal walls of fuel cladding tubes $1 \mathrm{~m}$ long and they exhibited an efficient inner protection to high-temperature oxidation in accidental conditions [79]. Although the models described here provide a sound basis for simulating practical deposition CVD reactors, important aspects of the chemistry merit further investigation. The measurements of BBC pyrolysis as well as the adsorption reactions are needed to assess more accurately the effects of temperature and pressure on deposition rates.

\section{Patents}

Method for depositing a coating by DLI-MOCVD with direct recycling of the precursor compound. F. Schuster, F. Maury, A. Michau, M. Pons, R. Boichot, F. Lomello; Patent No. WO/2017/103546, published on 22 June 2017.

Author Contributions: A.M. performed both the synthesis of the coatings (expected those of Figure 9 done by Y.G.) under the supervision of F.M. and F.S. and simulation of the process under the supervision of M.P., R.B. and I.N. M.P. wrote the manuscript, and all authors discussed the results and provided comments.

Funding: This research was funded by the "Investments for the Future" Program (No. ANR-10-LABEX-44-01) and by the Commissariat à l'Energie Atomique (CEA).

Acknowledgments: This research work was performed within the framework of the Centre of Excellence of Multifunctional Architectured Materials "CEMAM".

Conflicts of Interest: The authors declare no conflict of interest.

\section{References}

1. Briois, P.; Mercs, D.; Demange, V.; Banakh, O.; Sanchette, F.; Billard, A. Characterizations of CrN/a-CN nanolayered coatings deposited by DC reactive magnetron sputtering of $\mathrm{Cr}$ and graphite targets. Vacuum 2011, 86, 206-209. [CrossRef]

2. Bryskin, B.; Kostylev, A.; Pokrovskiy, Y.; Lumpov, A. CVD technology for preparing wear-resistive chromium carbide coatings of engine components. SAE Int. J. Mater. Manuf. 2014, 7, 630-632. [CrossRef] 
3. Castillejo, F.E.; Marulanda, D.M.; Olaya, J.J.; Alfonso, J.E. Wear and corrosion resistance of niobium-chromium carbide coatings on AISI D2 produced through TRD. Surf. Coat. Technol. 2014, 254, 104-111. [CrossRef]

4. Maury, F. MOCVD of hard metallurgical coatings: Examples in the Cr-C-N system. Electrochim. Acta 2005, 50, 4525-4530. [CrossRef]

5. Schuster, F.; Maury, F.; Nowak, J.F. Influence of organochromium precursor chemistry on the microstructure of MOCVD chromium carbide coatings. Surf. Coat. Technol. 1990, 43-44, 185-198. [CrossRef]

6. Mugabi, J.A.; Eriksen, I.; Petrushina, I.; Christensen, E.; Bjerrum, N.J. Kinetic study of the chemical vapor deposition of tantalum in long narrow channels. Adv. Mater. Interfaces 2016, 3, 1500795. [CrossRef]

7. Hinke, S.; StiJckel, S.; Marx, G. Characterization of BN-films deposited onto carbon fibres by a continuous CVD-process. Frenesius J. Anal. Chem. 1994, 349, 181. [CrossRef]

8. Suzuki, M.; Tanaka, Y.; Inoue, Y.; Myamoto, N.; Sato, M.; Goda, K. Uniformization of boron nitride coating thickness by continuous chemical vapor deposition process for interphase of $\mathrm{SiC} / \mathrm{SiC}$ composites. J. Ceram. Soc. Jpn. 2003, 111, 865-871. [CrossRef]

9. Heffernan, W.J.; Ahmad, I.; Haskell, R.W. Continuous CVD process for coating filaments with tantalum carbide. In Proceedings of the 4th International Conference on Chemical Vapor Deposition, Boston, MA, USA, 7 October 1973; Wakefield, G.F., Ed.; Electrochemical Society: Princeton, NJ, USA, 1973; pp. 498-508.

10. Kawamura, H.; Tachikawa, K. Preparation of the superconducting $\mathrm{Nb}_{3} \mathrm{Ge}$ tape by a continuous CVD process. Jpn. J. Appl. Phys. 1977, 16, 2037-2041. [CrossRef]

11. Polsen, E.S.; McNerny, D.Q.; Viswanath, B.; Pattinson, S.W.; Hart, A.J. High-speed roll-to-roll manufacturing of graphene using a concentric tube CVD reactor. Sci. Rep. 2015, 5, 10257. [CrossRef] [PubMed]

12. Liang, H.F.; Gordon, R.G. Atmospheric pressure chemical vapor deposition of transparent conducting films of fluorine doped zinc oxide and their application to amorphous silicon solar cells. J. Mater. Sci. 2007, 42, 6388-6399. [CrossRef]

13. Schropp, R.E.I. Industrialization of hot wire chemical vapor deposition for thin film applications. Thin Solid Films 2015, 595, 272-283. [CrossRef]

14. Casserly, T.; Boinapally, K.; Oppus, M.; Upadhyaya, D.; Boardman, B.; Tudhope, A. Investigation of DLC-Si film deposited inside a 304SS pipe using a novel hollow cathode plasma immersion ion processing method. In Proceedings of the 50th Annual Technical Conference Proceedings, Louisville, KY, USA, 28 April-3 May 2007; pp. 59-62.

15. Besmann, T.; Matlin, W.; Stinton, D. Chemical vapor infiltration process modeling and optimization. MRS Proc. 1995, 410, 441-451. [CrossRef]

16. Kwatera, A. Uniform thin chemically vapor-deposited layers of high density on the inner surfaces of tube-shaoed substrates. Thin Solid Films 1991, 204, 313-339. [CrossRef]

17. Itoh, H.; Gonda, M.; Sugiyama, K. CVD of corrosion-resistant tin and tic films to inner wall of steel tubes. J. Met. Finish. Soc. Jpn. 1984, 35, 590-594. [CrossRef]

18. Itoh, H.; Kato, K.; Sugiyama, K. Chemical vapour deposition of tin film to the inner walls of long steel tubes. J. Mater. Sci. 1986, 21, 751-756. [CrossRef]

19. Drieux, P.; Chollon, G.; Jacques, S.; Allemand, A.; Cavagnat, D.; Buffeteau, T. Experimental study of the chemical vapor deposition from $\mathrm{CH}_{3} \mathrm{SiHCl}_{2} / \mathrm{H}_{2}$ : Application to the synthesis of monolithic sic tubes. Surf. Coat. Technol. 2013, 230, 137-144. [CrossRef]

20. Duguet, T.; Vahlas, C.; Ledru, Y. Method and Device for the Formation of a Continuous Layer on the Inner and Outer Surfaces of a Hollow Part and Part Thus Produced. Patent WO 201,410,218,8A1, 3 July 2014.

21. Hertz, D.; Audisio, S.; Defoort, F.; Idriss, H. Method of Obtaining an Insulating Coating of Chromium Oxide between the Pellets and the Cladding of a Nuclear Fuel Element and Nuclear Fuel Element Having such an Insulating Coating. Patent EP 040,969,3A1, 23 January 1991.

22. Poirier, L.; Wang, Y.B.; Ducarroir, M.; Teyssandier, F. Ceramic coating of metal tube inner surfaces by MOCVD. In Proceedings of the 14th International Conference on Chemical Vapor Deposition, Paris, France, 5-9 September 1997; Allendorf, M.D., Bernard, C., Eds.; Electrochemical Society: Pennington, NJ, USA, 1997; Volume 25, pp. 425-432.

23. Xiong, Y.Q.; Dong, M.J.; Li, K.; Wang, J.Z.; Ren, N. Model for atomic layer deposition on inner wall of rectangular pipes with large aspect ratio. In Proceedings of the Eighth International Conference on Thin Film Physics and Applications, Shanghai, China, 20-23 September 2013; Chu, J., Wang, C., Eds.; SPIE: Bellingham, WA, USA, 2013; p. UNSP 90680C. 
24. Ives, R.L.; Oldham, C.J.; Daubert, J.S.; Gremaud, A.P.; Collins, G.; Marsden, D.; Bui, T.; Fusco, M.A.; Mitsdarffer, B.; Parsons, G.N. Corrosion mitigation coatings for RF sources and components. IEEE Trans. Electron Devices 2018, 65, 2385-2392. [CrossRef]

25. Karwa, M.; Iqbal, Z.; Mitra, S. Scaled-up self-assembly of carbon nanotubes inside long stainless steel tubing. Carbon 2006, 44, 1235-1242. [CrossRef]

26. Clark, T.J.; Banash, M.A.; Cruse, R.W.; Mininni, R.M.; Rohman, S.J. Model for chemical vapor deposition of nanostructured ceramics inside tubes under high temperature laminar flow conditions. Nanostruct. Mater. 1994, 4, 723-735. [CrossRef]

27. Johnson, C.E.; Crouthamel, C.E. Nuclear Reactor Fuel Element. U.S. Patent 42,292,601,980, 21 October 1980.

28. Field, A.L. Process for Coating the Internal Surface of a Metal Tube with a Neutron Absorber. Patent EP 020,456,5A2, 10 December 1986.

29. Douard, A.; Bernard, C.; Maury, F. Thermodynamic simulation of atmospheric DLI-CVD processes for the growth of chromium-based hard coatings using bis(benzene)chromium as molecular source. Surf. Coat. Technol. 2008, 203, 516-520. [CrossRef]

30. Allendorf, M.D.; van Mol, A.M.B. Gas-phase thermochemistry and mechanism of organometallic tin oxide CVD precursors. Top. Organomet. Chem. 2005, 9, 1-48.

31. Chae, Y.; Houf, W.G.; McDaniel, A.H.; Allendorf, M.D. Models for the chemical vapor deposition of tin oxide from monobutyltintrichloride. J. Electrochem. Soc. 2006, 153, C309-C317. [CrossRef]

32. Dauelsberg, M.; Brien, D.; Rauf, H.; Reiher, F.; Baumgartl, J.; Häberlen, O.; Segal, A.S.; Lobanova, A.V.; Yakovlev, E.V.; Talalaev, R.A. On mechanisms governing ALN and ALGaN growth rate and composition in large substrate size planetary MOVPE reactors. J. Cryst. Growth 2014, 393, 103-107. [CrossRef]

33. Dauelsberg, M.; Kadinski, L.; Makarov, Y.N.; Bergunde, T.; Strauch, G.; Weyers, M. Modeling and experimental verification of transport and deposition behavior during MOVPE of Ga1-xinxP in the planetary reactor. J. Cryst. Growth 2000, 208, 85-92. [CrossRef]

34. Endres, D.; Mazumder, S. Numerical investigation of pulsed chemical vapor deposition of aluminum nitride to reduce particle formation. J. Cryst. Growth 2011, 335, 42-50. [CrossRef]

35. Etchepare, P.L.; Vergnes, H.; Samélor, D.; Sadowski, D.; Caussat, B.; Vahlas, C. Modeling a MOCVD process to apply alumina films on the inner surface of bottles. Surf. Coat. Technol. 2015, 275, 167-175. [CrossRef]

36. Han, X.-F.; Lee, J.-H.; Lee, Y.-J.; Song, J.-H.; Yi, K.-W. Numerical analysis on the origin of thickness unevenness and formation of pits at GaN thin film grown by HVPE. J. Cryst. Growth 2016, 450, 66-73. [CrossRef]

37. Inagaki, Y.; Kozawa, T. Chemical reaction pathways for MOVPE growth of aluminum nitride. ECS J. Solid State Sci. Technol. 2015, 5, P73-P75. [CrossRef]

38. Li, M.; Sopko, J.F.; McCamy, J.W. Computational fluid dynamic modeling of tin oxide deposition in an impinging chemical vapor deposition reactor. Thin Solid Films 2006, 515, 1400-1410. [CrossRef]

39. Manin, M.; Thollon, S.; Emieux, F.; Berthome, G.; Pons, M.; Guillon, H. Deposition of MgO thin film by liquid pulsed injection MOCVD. Surf. Coat. Technol. 2005, 200, 1424-1429. [CrossRef]

40. Mazumder, S.; Lowry, S.A. The importance of predicting rate-limited growth for accurate modeling of commercial MOCVD reactors. J. Cryst. Growth 2001, 224, 165-174. [CrossRef]

41. Mihopoulos, T.G.; Gupta, V.; Jensen, K.F. A reaction-transport model for AlGaN MOVPE growth. J. Cryst. Growth 1998, 195, 733-739. [CrossRef]

42. Momose, T.; Kamiya, T.; Suzuki, Y.; Ravasio, S.; Cavallotti, C.; Sugiyama, M.; Shimogaki, Y. Kinetic analysis of GaN-MOVPE via thickness profiles in the gas flow direction with systematically varied growth conditions. ECS J. Solid State Sci. Technol. 2016, 5, P164-P171. [CrossRef]

43. Nieto, J.P.; Jeannerot, L.; Caussat, B. Modelling of an industrial moving belt chemical vapour deposition reactor forming $\mathrm{SiO}_{2}$ films. Chem. Eng. Sci. 2005, 60, 5331-5340. [CrossRef]

44. Theodoropoulos, C.; Mountziaris, T.J.; Moffat, H.K.; Han, J. Design of gas inlets for the growth of gallium nitride by metalorganic vapor phase epitaxy. J. Cryst. Growth 2000, 217, 65-81. [CrossRef]

45. Vorob'ev, A.N.; Archakov, I.Y.; Bord, O.V.; Smirnov, S.A.; Karpov, S.Y.; Makarov, Y.N.; Reinhold, M.; Schumacher, M.; Heuken, M. Advanced model for the simulation of BST-film growth with MOCVD. Synth. Met. 2003, 138, 145-151. [CrossRef]

46. Xenidou, T.C.; Prud'homme, N.; Vahlas, C.; Markatos, N.C.; Boudouvis, A.G. Reaction and transport interplay in al MOCVD investigated through experiments and computational fluid dynamic analysis. J. Electrochem. Soc. 2010, 157, D633-D641. [CrossRef] 
47. Douard, A.; Maury, F. Nanocrystalline chromium-based coatings deposited by DLI-MOCVD under atmospheric pressure from Cr(CO)6. Surf. Coat. Technol. 2006, 200, 6267-6271. [CrossRef]

48. Bird, R.B.; Stewart, W.E.; Lightfoot, E.N. Transport Phenomena, 2nd ed.; John Wiley \& Sons Inc.: New York, NY, USA, 2007.

49. Kee, R.J.; Dixon-Lewis, G.; Warnatz, J.; Coltrin, M.E.; Miller, J.A.; Moffat, H.K. A Fortran Computer Code Package for the Evaluation of Gas-Phase, Multicomponent Transport Properties; SAND86-8246B; Sandia National Laboratories: Albuquerque, NM, USA, 1986.

50. Brioukov, M.G.; Park, J.; Lin, M.C. Kinetic modeling of benzene decomposition near 1000 k: The effects of toluene impurity. Int. J. Chem. Kinet. 1999, 31, 577-582. [CrossRef]

51. Maury, F.; Vahlas, C.; Abisset, S.; Gueroudji, L. Low temperature metallorganic chemical vapor deposition routes to chromium metal thin films using bis(benzene)chromium. J. Electrochem. Soc. 1999, 146, 3716-3723. [CrossRef]

52. Devyatykh, G.G.; Larin, N.V.; Gaivoronskii, P.E. Mass spectrum of bis(benzene)chromium and the appearance potentials of ions. J. Gen. Chem. USSR 1969, 39, 1786-1787.

53. Sahnoun, R.; Mijoule, C. Density functional study of metal-arene compounds: Mono(benzene)chromium, bis(benzene)chromium and their cations. J. Phys. Chem. A 2001, 105, 6176-6181. [CrossRef]

54. Devi, A.; Schmid, R.; Müller, J.; Fischer, R.A. Materials chemistry of group 13 nitrides. Top. Organomet. Chem. 2005, 9, 49-80.

55. Koel, B.E.; Crowell, J.E.; Bent, B.E.; Mate, C.M.; Somorjai, G.A. Thermal decomposition of benzene on the rhodium(111) crystal surface. J. Phys. Chem. 1986, 90, 2949-2956. [CrossRef]

56. Kurikawa, T.; Takeda, H.; Hirano, M.; Judai, K.; Arita, T.; Nagao, S.; Nakajima, A.; Kaya, K. Electronic properties of organometallic metal-benzene complexes $\left.\left[\mathrm{M}_{n} \text { (benzene }\right)_{m}(\mathrm{M}=\mathrm{Sc}-\mathrm{Cu})\right]$. Organometallics 1999, 18, 1430-1438. [CrossRef]

57. Timms, P.L. Transition metal vapors in chemical synthesis. The direct preparation of dibenzene chromium as an undergraduate experiment. J. Chem. Educ. 1972, 49, 782-784. [CrossRef]

58. Blass, P.M.; Akhter, S.; Seymour, C.M.; Lagowski, J.J.; White, J.M. The adsorption and decomposition of BIS(Benzene)chromium on Ni(100). Surf. Sci. 1989, 217, 85-102. [CrossRef]

59. Lamanna, W.M. Metal vapor synthesis of a novel triple-decker sandwich complex: (.Eta.6-mesitylene)2(.Mu.Eta.6:.Eta.6-mesitylene)Cr 2 . J. Am. Chem. Soc. 1986, 108, 2096-2097. [CrossRef]

60. Liu, A.C.; Friend, C.M. The structure and reactivity of chemisorbed aromatics: Spectroscopic studies of benzene on Mo(110). J. Chem. Phys. 1988, 89, 4396-4405. [CrossRef]

61. Maury, F.; Douard, A.; Delclos, S.; Samelor, D.; Tendero, C. Multilayer chromium based coatings grown by atmospheric pressure direct liquid injection CVD. Surf. Coat. Technol. 2009, 204, 983-987. [CrossRef]

62. Maury, F.; Gueroudji, L.; Vahlas, C. Selection of metalorganic precursors for MOCVD of metallurgical coatings: Application to Cr-based coatings. Surf. Coat. Technol. 1996, 86-87, 316-324. [CrossRef]

63. Vahlas, C.; Maury, F.; Gueroudji, L. A thermodynamic approach to the CVD of chromium and of chromium carbides starting from $\mathrm{Cr}\left(\mathrm{C}_{6} \mathrm{H}_{6}\right)_{2}$. Chem. Vapor Depos. 1998, 4, 69-76. [CrossRef]

64. Maury, F.; Oquab, D.; Manse, J.C.; Morancho, R.; Nowak, J.F.; Gauthier, J.P. Structural characterization of chromium carbide coatings deposited at low temperature by low pressure chemical vapour decomposition using dicumene chromium. Surf. Coat. Technol. 1990, 41, 51-61. [CrossRef]

65. Michau, A.; Maury, F.; Schuster, F.; Boichot, R.; Pons, M.; Monsifrot, E. Chromium carbide growth at low temperature by a highly efficient DLI-MOCVD process in effluent recycling mode. Surf. Coat. Technol. 2017, 332, 96-104. [CrossRef]

66. Maury, F.; Ossola, F. Evaluation of tetra-alkylchromium precursors for organometallic chemical vapour deposition I. Films grown using $\mathrm{Cr}\left[\mathrm{CH}_{2} \mathrm{C}\left(\mathrm{CH}_{3}\right)_{3}\right]_{4}$. Thin Solid Films 1992, 207, 82-89. [CrossRef]

67. Chase, M.W.J. NIST-JANAF Thermochemical Tables, 4th ed.; Journal of Physical and Chemical Reference Data Monographs; American Institute of Physics: College Park, MD, USA, 1998; pp. 1-1951.

68. Schäfer, L.; Southern, J.F. Some additional evidence for the sixfold symmetry of benzene in dibenzenechromium in the vapor phase. J. Organomet. Chem. 1970, 24, C13-C15. [CrossRef]

69. Ngai, L.H.; Stafford, F.E.; Schäfer, L. The symmetry of gaseous dibenzenechromium. J. Am. Chem. Soc. 1969, 91, 48-49. [CrossRef]

70. Hirschefelder, J.O. Simple method for calculating moments of inertia. J. Chem. Phys. 1940, 8, 431-432. [CrossRef] 
71. Haaland, A. The molecular structure of gaseous dibenzene chromium $\left(\mathrm{C}_{6} \mathrm{H}_{6}\right)_{2} \mathrm{Cr}$. Acta Chem. Scand. 1965, 19, 41-46. [CrossRef]

72. Andrews, J.T.S.; Westrum, E.F.; Bjerrum, N. Heat capacity and vapor pressure of crystalline bis(benzene) chromium. Third-law entropy comparison and thermodynamic evidence concerning the structure of bis(benzene)chromium. J. Organomet. Chem. 1969, 17, 293-302. [CrossRef]

73. Kee, R.J.; Rupley, F.M.; Miller, J.A. The Chemkin Thermodynamic Data Base; SAND87-8215B; Sandia National Laboratories: Albuquerque, NM, USA, 1990.

74. McBride, B.J.; Gordon, S.; Reno, M.A. Coefficients for Calculating Thermodynamic and Transport Properties of Individual Species; NASA Techinical Memorandum 4513; NASA: Washington, DC, USA, 1993.

75. Svehla, R.A. Estimated Viscosities and Thermal Conductivities of Gases at High Temperatures; Technical Report R-132; NASA: Washington, DC, USA, 1962.

76. Bouteville, A. Numerical simulation applied to chemical vapor deposition process. Rapid thermal CVD and spray CVD. J. Optoelectron. Adv. Mater. 2005, 7, 599-606.

77. Li, Z.; Zhang, J.; Li, J.; Jiang, H.; Fu, X.; Han, Y.; Xia, Y.; Huang, Y.; Yin, J.; Zhang, L.; et al. Modeling and simulation of a novel susceptor composed of two materials in MOVPE reactor. J. Cryst. Growth 2014, 402, 175-178. [CrossRef]

78. Benson, S.W.; O’Neal, H.E. Kinetic Data on Gas Phase Unimolecular Reactions; NSRDS-NBS21, National Standard Reference Data Series; US Department of Commerce: Washington, DC, USA, 1970.

79. Michau, A.; Maury, F.; Schuster, F.; Lomello, F.; Brachet, J.C.; Rouesne, E.; Saux, M.L.; Boichot, R.; Pons, M. High-temperature oxidation resistance of chromium-based coatings deposited by dli-MOCVD for enhanced protection of the inner surface of long tubes. Surf. Coat. Technol. 2018, in press.

(C) 2018 by the authors. Licensee MDPI, Basel, Switzerland. This article is an open access article distributed under the terms and conditions of the Creative Commons Attribution (CC BY) license (http:/ / creativecommons.org/licenses/by/4.0/). 